\title{
Convergence of Modified $S$-iteration Process for Two Generalized Asymptotically Quasi-nonexpansive Mappings in CAT(0) Spaces
}

\author{
Gurucharan Singh Saluja
}

\begin{abstract}
In this paper, we give the sufficient condition of newly defined modified $S$-iteration process to converge to common fixed point for two generalized asymptotically quasi-nonexpansive mappings in the framework of $\mathrm{CAT}(0)$ spaces. Also we establish some strong convergence theorems of the said iteration process and mappings under suitable conditions. Our results extend and improve many known results from the existing literature.
\end{abstract}

\section{INTRODUCTION}

A metric space $X$ is a $\operatorname{CAT}(0)$ space if it is geodesically connected and if every geodesic triangle in $X$ is at least as 'thin' as its comparison triangle in the Euclidean plane. It is well known that any complete, simply connected Riemannian manifold having non-positive sectional curvature is a CAT(0) space. Other examples include Pre-Hilbert spaces (see [2]), $\mathbb{R}$-trees (see [15]), Euclidean buildings (see [3]), the complex Hilbert ball with a hyperbolic metric (see [10]), and many others. For a thorough discussion of these spaces and of the fundamental role they play in geometry, we refer the reader to Bridson and Haefliger [2].

Fixed point theory in CAT(0) space has been first studied by Kirk (see $[16,17])$. He showed that every nonexpansive (single-valued) mapping defined on a bounded closed convex subset of a complete CAT(0) space always has a fixed point. It is worth mentioning that the results in $\mathrm{CAT}(0)$ spaces can be applied to any $\operatorname{CAT}(k)$ space with $k \leq 0$ since any $\operatorname{CAT}(k)$ space is a $\operatorname{CAT}\left(k^{\prime}\right)$ space for every $k^{\prime} \geq k$ (see,e.g., [2]).

2010 Mathematics Subject Classification. 54H25, 54E40.

Key words and phrases. Generalized asymptotically quasi-nonexpansive mapping, strong convergence, modified S-iteration process, common fixed point, CAT(0) space. 
The Mann iteration process is defined by the sequence $\left\{x_{n}\right\}$,

$$
\left\{\begin{array}{l}
x_{1} \in K, \\
x_{n+1}=\left(1-\alpha_{n}\right) x_{n}+\alpha_{n} T x_{n}, \quad n \geq 1,
\end{array}\right.
$$

where $\left\{\alpha_{n}\right\}$ is a sequence in $(0,1)$.

Further, the Ishikawa iteration process is defined by the sequence $\left\{x_{n}\right\}$,

$$
\left\{\begin{aligned}
x_{1} \in K, & \\
x_{n+1} & =\left(1-\alpha_{n}\right) x_{n}+\alpha_{n} T y_{n}, \\
y_{n} & =\left(1-\beta_{n}\right) x_{n}+\beta_{n} T x_{n}, \quad n \geq 1,
\end{aligned}\right.
$$

where $\left\{\alpha_{n}\right\}$ and $\left\{\beta_{n}\right\}$ are the sequence in $(0,1)$. This iteration process reduces to the Mann iteration process when $\beta_{n}=0$ for all $n \geq 1$.

In 2007, Agarwal, O'Regan and Sahu [1] introduced the $S$-iteration process in Banach space,

$$
\left\{\begin{aligned}
x_{1} \in K & \\
x_{n+1} & =\left(1-\alpha_{n}\right) T x_{n}+\alpha_{n} T y_{n}, \\
y_{n} & =\left(1-\beta_{n}\right) x_{n}+\beta_{n} T x_{n}, \quad n \geq 1,
\end{aligned}\right.
$$

where $\left\{\alpha_{n}\right\}$ and $\left\{\beta_{n}\right\}$ are the sequence in $(0,1)$. Note that (3) is independent of (2) (and hence (1)). They showed that their process independent of those of Mann and Ishikawa and converges faster than both of these (see [[1], Proposition 3.1]).

Schu [24], in 1991, considered the modified Mann iteration process which is a generalization of the Mann iteration process,

$$
\left\{\begin{array}{l}
x_{1} \in K, \\
x_{n+1}=\left(1-\alpha_{n}\right) x_{n}+\alpha_{n} T^{n} x_{n}, \quad n \geq 1,
\end{array}\right.
$$

where $\left\{\alpha_{n}\right\}$ is a sequence in $(0,1)$.

Tan and Xu [28], in 1994, studied the modified Ishikawa iteration process which is a generalization of the Ishikawa iteration process,

$$
\left\{\begin{aligned}
x_{1} \in K, & \\
x_{n+1} & =\left(1-\alpha_{n}\right) x_{n}+\alpha_{n} T^{n} y_{n}, \\
y_{n} & =\left(1-\beta_{n}\right) x_{n}+\beta_{n} T^{n} x_{n}, \quad n \geq 1,
\end{aligned}\right.
$$

where $\left\{\alpha_{n}\right\}$ and $\left\{\beta_{n}\right\}$ are the sequence in $(0,1)$. This iteration process reduces to the modified Mann iteration process when $\beta_{n}=0$ for all $n \geq 1$. 
In 2007, Agarwal, O'Regan and Sahu [1] introduced the modified $S$ iteration process in Banach space,

$$
\left\{\begin{aligned}
x_{1} \in K, & \\
x_{n+1} & =\left(1-\alpha_{n}\right) T^{n} x_{n}+\alpha_{n} T^{n} y_{n}, \\
y_{n} & =\left(1-\beta_{n}\right) x_{n}+\beta_{n} T^{n} x_{n}, \quad n \geq 1,
\end{aligned}\right.
$$

where $\left\{\alpha_{n}\right\}$ and $\left\{\beta_{n}\right\}$ are the sequence in $(0,1)$. Note that $(6)$ is independent of (5) (and hence of (4)). Also (6) reduces to (3) when $T^{n}=T$ for all $n \geq 1$.

In 2009, Imnang and Suantai [11] have studied multi-step iteration process for a finite family of generalized asymptotically quasi-nonexpansive mappings and gave a necessary and sufficient condition for the said scheme and mappings to converge to the common fixed points and also they established some strong convergence theorems in the frame work of uniformly convex Banach spaces.

Very recently, Şahin and Başarir [22] modified the iteration process (6) in a $\mathrm{CAT}(0)$ space as follows:

Let $K$ be a nonempty closed convex subset of a complete CAT(0) space $X$ and $T: K \rightarrow K$ be an asymptotically quasi-nonexpansive mapping with $F(T) \neq \emptyset$. Suppose that $\left\{x_{n}\right\}$ is a sequence generated iteratively by

$$
\left\{\begin{aligned}
x_{1} \in K, & \\
x_{n+1} & =\left(1-\alpha_{n}\right) T^{n} x_{n} \oplus \alpha_{n} T^{n} y_{n}, \\
y_{n} & =\left(1-\beta_{n}\right) x_{n} \oplus \beta_{n} T^{n} x_{n}, \quad n \geq 1,
\end{aligned}\right.
$$

where $\left\{\alpha_{n}\right\}$ and $\left\{\beta_{n}\right\}$ are the sequences such that $0 \leq \alpha_{n}, \beta_{n} \leq 1$ for all $n \geq 1$. They studied modified $S$-iteration process for asymptotically quasinonexpansive mappings on the CAT(0) space and established some strong convergence results under some suitable conditions which generalize some results of Khan and Abbas [13].

We now further modify (7) for two mappings in a CAT(0) space as follows:

Let $K$ be a nonempty closed convex subset of a complete CAT(0) space $X$ and $S, T: K \rightarrow K$ be two asymptotically quasi-nonexpansive mappings with $F(S, T)=F(S) \cap F(T) \neq \emptyset$. Suppose that $\left\{x_{n}\right\}$ is a sequence generated iteratively by

$$
\left\{\begin{aligned}
x_{1} \in K, & \\
x_{n+1} & =\left(1-\alpha_{n}\right) T^{n} x_{n} \oplus \alpha_{n} S^{n} y_{n}, \\
y_{n} & =\left(1-\beta_{n}\right) x_{n} \oplus \beta_{n} T^{n} x_{n}, \quad n \geq 1,
\end{aligned}\right.
$$


where $\left\{\alpha_{n}\right\}$ and $\left\{\beta_{n}\right\}$ are the sequences such that $0 \leq \alpha_{n}, \beta_{n} \leq 1$ for all $n \geq 1$.

If we take $S=T$, then (8) reduces to (7).

The aim of this paper is to study the newly defined modified $S$-iteration process (8) for two generalized asymptotically quasi-nonexpansive mappings and give the sufficient condition to converge to common fixed point in the framework of CAT(0) space and also establish some strong convergence results under some suitable conditions. Our results extend and generalize many known results from the previous work given in the existing literature.

\section{Preliminaries AND Lemmas}

In order to prove the main results of this paper, we need the following definitions, concepts and lemmas:

Let $(X, d)$ be a metric space and $K$ be its nonempty subset. Let $T: K \rightarrow$ $K$ be a mapping. A point $x \in K$ is called a fixed point of $T$ if $T x=x$. We will also denote by $F(S, T)$ the set of common fixed points of $S$ and $T$, that is, $F(S, T)=\{x \in K: S x=T x=x\}$.

The concept of quasi-nonexpansive was introduced by Diaz and Metcalf [7] in 1967, the concept of asymptotically nonexpansive mapping was introduced by Goebel and Kirk [9] in 1972. The iterative approximation problem for asymptotically quasi-nonexpansive mapping and asymptotically quasi-nonexpansive type mapping were studied by many authors (see, e.g. $[8,14,18,19,21,23,26])$ in a Banach space and a CAT(0) space.

Definition 2.1. Let $(X, d)$ be a metric space and $K$ be its subset. Then $T: K \rightarrow K$ said to be

(1) nonexpansive if $d(T x, T y) \leq d(x, y)$ for all $x, y \in K$;

(2) asymptotically nonexpansive if there exists a sequence $\left\{u_{n}\right\} \subset[0, \infty)$ with $\lim _{n \rightarrow \infty} u_{n}=0$ such that $d\left(T^{n} x, T^{n} y\right) \leq\left(1+u_{n}\right) d(x, y)$ for all $x, y \in K$ and $n \geq 1$;

(3) quasi-nonexpansive if $d(T x, p) \leq d(x, p)$ for all $x \in K$ and $p \in F(T)$;

(4) asymptotically quasi-nonexpansive if $F(T) \neq \emptyset$ and there exists a sequence $\left\{u_{n}\right\} \subset[0, \infty)$ with $\lim _{n \rightarrow \infty} u_{n}=0$ such that $d\left(T^{n} x, p\right) \leq(1+$ 
$\left.u_{n}\right) d(x, p)$ for all $x \in K, p \in F(T)$ and $n \geq 1$;

(5) generalized asymptotically quasi-nonexpansive [11] if $F(T) \neq \emptyset$ and there exist sequences $\left\{u_{n}\right\},\left\{s_{n}\right\} \subset[0, \infty)$ with $\lim _{n \rightarrow \infty} u_{n}=0=\lim _{n \rightarrow \infty} s_{n}$ such that $d\left(T^{n} x, p\right) \leq\left(1+u_{n}\right) d(x, p)+s_{n}$ for all $x \in K, p \in F(T)$ and $n \geq 1$;

(6) $T$ is said to be asymptotically nonexpansive mapping in the the intermediate sense [4] provided that $T$ is uniformly continuous and

$$
\limsup _{n \rightarrow \infty} \sup _{x, y \in K}\left(d\left(T^{n} x, T^{n} y\right)-d(x, y)\right) \leq 0 ;
$$

(7) uniformly $L$-Lipschitzian if there exists a constant $L>0$ such that $d\left(T^{n} x, T^{n} y\right)$

$\leq L d(x, y)$ for all $x, y \in K$ and $n \geq 1$;

(8) semi-compact if for a sequence $\left\{x_{n}\right\}$ in $K$ with $\lim _{n \rightarrow \infty} d\left(x_{n}, T x_{n}\right)=0$, there exists a subsequence $\left\{x_{n_{k}}\right\}$ of $\left\{x_{n}\right\}$ such that $x_{n_{k}} \rightarrow p \in K$.

If $s_{n}=0$ for all $n \geq 1$ in (5), then $T$ is known as an asymptotically quasi-nonexpansive mapping.

Remark 2.1. Let $T$ be asymptotically nonexpansive mapping in the intermediate sense. Put $c_{n}=\sup _{x, y \in K}\left(d\left(T^{n} x, T^{n} y\right)-d(x, y)\right) \vee 0, \forall n \geq 1$.

If $F(T) \neq \emptyset$, we obtain that $d\left(T^{n} x, p\right) \leq d(x, p)+c_{n}$ for all $x \in K$ and all $p \in F(T)$. Since $\lim _{n \rightarrow \infty} c_{n}=0$, therefore $T$ is generalized asymptotically quasi-nonexpansive mapping.

Let $(X, d)$ be a metric space. A geodesic path joining $x \in X$ to $y \in X$ (or, more briefly, a geodesic from $x$ to $y$ ) is a map $c$ from a closed interval $[0, l] \subset \mathbb{R}$ to $X$ such that $c(0)=x, c(l)=y$ and let $d\left(c(t), c\left(t^{\prime}\right)\right)=\left|t-t^{\prime}\right|$ for all $t, t^{\prime} \in[0, l]$. In particular, $c$ is an isometry, and $d(x, y)=l$. The image $\alpha$ of $c$ is called a geodesic (or metric) segment joining $x$ and $y$. We say $X$ is (i) a geodesic space if any two points of $X$ are joined by a geodesic and (ii) uniquely geodesic if there is exactly one geodesic joining $x$ and $y$ for each $x, y \in X$, which we will denoted by $[x, y]$, called the segment joining $x$ to $y$.

A geodesic triangle $\triangle\left(x_{1}, x_{2}, x_{3}\right)$ in a geodesic metric space $(X, d)$ consists of three points in $X$ (the vertices of $\triangle$ ) and a geodesic segment between each pair of vertices (the edges of $\triangle$ ). A comparison triangle for a geodesic triangle $\triangle\left(x_{1}, x_{2}, x_{3}\right)$ in $(X, d)$ is a triangle $\bar{\triangle}\left(x_{1}, x_{2}, x_{3}\right):=\triangle\left(\overline{x_{1}}, \overline{x_{2}}, \overline{x_{3}}\right)$ in $\mathbb{R}^{2}$ such that $d_{\mathbb{R}^{2}}\left(\overline{x_{i}}, \overline{x_{j}}\right)=d\left(x_{i}, x_{j}\right)$ for $i, j \in\{1,2,3\}$. Such a triangle always exists (see [2]). 


\section{CAT(0) space}

A geodesic metric space is said to be a $C A T(0)$ space if all geodesic triangles of appropriate size satisfy the following $C A T(0)$ comparison axiom.

Let $\triangle$ be a geodesic triangle in $X$, and let $\bar{\triangle} \subset \mathbb{R}^{2}$ be a comparison triangle for $\triangle$. Then $\triangle$ is said to satisfy the $C A T(0)$ inequality if for all $x, y \in \triangle$ and all comparison points $\bar{x}, \bar{y} \in \bar{\triangle}$,

$$
d(x, y) \leq d_{\mathbb{R}^{2}}(\bar{x}, \bar{y}) .
$$

Complete $C A T(0)$ spaces are often called Hadamard spaces (see [12]). If $x, y_{1}, y_{2}$ are points of a $C A T(0)$ space and $y_{0}$ is the midpoint of the segment $\left[y_{1}, y_{2}\right]$ which we will denote by $\left(y_{1} \oplus y_{2}\right) / 2$, then the $C A T(0)$ inequality implies

$$
d^{2}\left(x, \frac{y_{1} \oplus y_{2}}{2}\right) \leq \frac{1}{2} d^{2}\left(x, y_{1}\right)+\frac{1}{2} d^{2}\left(x, y_{2}\right)-\frac{1}{4} d^{2}\left(y_{1}, y_{2}\right) .
$$

The inequality (9) is the $(C N)$ inequality of Bruhat and Tits [5]. The above inequality has been extended in [6] as

$$
\begin{aligned}
d^{2}(z, \alpha x \oplus(1-\alpha) y) & \leq \alpha d^{2}(z, x)+(1-\alpha) d^{2}(z, y) \\
& -\alpha(1-\alpha) d^{2}(x, y)
\end{aligned}
$$

for any $\alpha \in[0,1]$ and $x, y, z \in X$.

Let us recall that a geodesic metric space is a $C A T(0)$ space if and only if it satisfies the $(C N)$ inequality (see [2, p.163]). Moreover, if $X$ is a $C A T(0)$ metric space and $x, y \in X$, then for any $\alpha \in[0,1]$, there exists a unique point $\alpha x \oplus(1-\alpha) y \in[x, y]$ such that

$$
d(z, \alpha x \oplus(1-\alpha) y) \leq \alpha d(z, x)+(1-\alpha) d(z, y),
$$

for any $z \in X$ and $[x, y]=\{\alpha x \oplus(1-\alpha) y: \alpha \in[0,1]\}$.

A subset $C$ of a $C A T(0)$ space $X$ is convex if for any $x, y \in C$, we have $[x, y] \subset C$.

We need the following useful lemmas to prove our main results in this paper.

Lemma 2.1. (See [20]) Let $X$ be a CAT(0) space.

(i) For $x, y \in X$ and $t \in[0,1]$, there exists a unique point $z \in[x, y]$ such that

$$
d(x, z)=t d(x, y) \quad \text { and } \quad d(y, z)=(1-t) d(x, y) .
$$

We use the notation $(1-t) x \oplus$ ty for the unique point $z$ satisfying $(A)$. 
(ii) For $x, y \in X$ and $t \in[0,1]$, we have

$$
d((1-t) x \oplus t y, z) \leq(1-t) d(x, z)+t d(y, z) .
$$

Lemma 2.2. (See [27]) Let $\left\{a_{n}\right\},\left\{b_{n}\right\}$ and $\left\{\delta_{n}\right\}$ be sequences of nonnegative real numbers satisfying the inequality

$$
a_{n+1} \leq\left(1+\delta_{n}\right) a_{n}+b_{n}, \quad n \geq 1 .
$$

If $\sum_{n=1}^{\infty} \delta_{n}<\infty$ and $\sum_{n=1}^{\infty} b_{n}<\infty$, then $\lim _{n \rightarrow \infty} a_{n}$ exists. In particular, if $\left\{a_{n}\right\}$ has a subsequence converging to zero, then $\lim _{n \rightarrow \infty} a_{n}=0$.

\section{Main Results}

In this section, we establish some strong convergence results of newly defined modified $S$-iteration scheme (8) to converge to common fixed point for two generalized asymptotically quasi-nonexpansive mappings in the setting of $\mathrm{CAT}(0)$ space.

Theorem 3.1. Let $K$ be a nonempty closed convex subset of a complete $C A T(0)$ space $X$ and let $S, T: K \rightarrow K$ be two uniformly L-Lipschitzian and generalized asymptotically quasi-nonexpansive mappings with sequences $\left\{u_{n}\right\},\left\{s_{n}\right\} \subset[0, \infty)$ such that $\sum_{n=1}^{\infty} u_{n}<\infty$ and $\sum_{n=1}^{\infty} s_{n}<\infty$. Suppose that $F(S, T) \neq \emptyset$. Let $\left\{x_{n}\right\}$ be defined by the iteration process (8). If $\liminf \operatorname{in}_{n \rightarrow \infty} d\left(x_{n}, F(S, T)\right)=0$ or $\limsup _{n \rightarrow \infty} d\left(x_{n}, F(S, T)\right)=0$, where $d(x, F(S, T))=\inf _{p \in F(S, T)} d(x, p)$, then the sequence $\left\{x_{n}\right\}$ converges strongly to a point in $F(S, T)$.

Proof. Let $p \in F(S, T)$. From (8) and Lemma 2.1(ii), we have

$$
\begin{aligned}
d\left(y_{n}, p\right) & =d\left(\left(1-\beta_{n}\right) x_{n} \oplus \beta_{n} T^{n} x_{n}, p\right) \\
& \leq\left(1-\beta_{n}\right) d\left(x_{n}, p\right)+\beta_{n} d\left(T^{n} x_{n}, p\right) \\
& \leq\left(1-\beta_{n}\right) d\left(x_{n}, p\right)+\beta_{n}\left[\left(1+u_{n}\right) d\left(x_{n}, p\right)+s_{n}\right] \\
& \leq\left(1+u_{n}\right) d\left(x_{n}, p\right)+s_{n} .
\end{aligned}
$$

Again using (7), (12) and Lemma 2.1(ii), we have

$$
\begin{aligned}
d\left(x_{n+1}, p\right) & =d\left(\left(1-\alpha_{n}\right) T^{n} x_{n} \oplus \alpha_{n} S^{n} y_{n}, p\right) \\
& \leq\left(1-\alpha_{n}\right) d\left(T^{n} x_{n}, p\right)+\alpha_{n} d\left(S^{n} y_{n}, p\right) \\
& \leq\left(1-\alpha_{n}\right)\left[\left(1+u_{n}\right) d\left(x_{n}, p\right)+s_{n}\right]+\alpha_{n}\left[\left(1+u_{n}\right) d\left(y_{n}, p\right)+s_{n}\right] \\
& \leq\left(1-\alpha_{n}\right)\left(1+u_{n}\right) d\left(x_{n}, p\right)+\alpha_{n}\left(1+u_{n}\right) d\left(y_{n}, p\right)+s_{n} \\
& \leq\left(1-\alpha_{n}\right)\left(1+u_{n}\right) d\left(x_{n}, p\right)+\alpha_{n}\left(1+u_{n}\right)\left[\left(1+u_{n}\right) d\left(x_{n}, p\right)+s_{n}\right]+s_{n} \\
& \leq\left(1+u_{n}\right)^{2} d\left(x_{n}, p\right)+\left(2+u_{n}\right) s_{n} \\
(14) \quad & =\left(1+A_{n}\right) d\left(x_{n}, p\right)+B_{n},
\end{aligned}
$$


where $A_{n}=2 u_{n}+u_{n}^{2}$ and $B_{n}=\left(2+u_{n}\right) s_{n}$. Since by hypothesis of the theorem $\sum_{n=1}^{\infty} u_{n}<\infty$ and $\sum_{n=1}^{\infty} s_{n}<\infty$, it follows that $\sum_{n=1}^{\infty} A_{n}<\infty$ and $\sum_{n=1}^{\infty} B_{n}<\infty$. This gives

$$
d\left(x_{n+1}, F(S, T)\right) \leq\left(1+A_{n}\right) d\left(x_{n}, F(S, T)\right)+B_{n} .
$$

Since by hypothesis $\sum_{n=1}^{\infty} A_{n}<\infty$ and $\sum_{n=1}^{\infty} B_{n}<\infty$ by Lemma 2.2 and $\liminf _{n \rightarrow \infty} d\left(x_{n}, F(S, T)\right)=0$ or $\limsup _{n \rightarrow \infty} d\left(x_{n}, F(S, T)\right)=0$ gives that

$$
\lim _{n \rightarrow \infty} d\left(x_{n}, F(S, T)\right)=0 .
$$

Now, we show that $\left\{x_{n}\right\}$ is a Cauchy sequence in $K$. With the help of inequality $1+x \leq e^{x}, x \geq 0$. For any integer $m \geq 1$, we have from (13) that

$$
\begin{aligned}
d\left(x_{n+m}, p\right) & \leq\left(1+A_{n+m-1}\right) d\left(x_{n+m-1}, p\right)+B_{n+m-1} \\
& \leq e^{A_{n+m-1}} d\left(x_{n+m-1}, p\right)+B_{n+m-1} \\
& \leq e^{A_{n+m-1}} e^{A_{n+m-2}} d\left(x_{n+m-2}, p\right)+e^{A_{n+m-1}} B_{n+m-2}+B_{n+m-1} \\
& \leq \cdots \\
& \leq\left(e^{\sum_{k=n}^{n+m-1} A_{k}}\right) d\left(x_{n}, p\right)+\left(e^{\sum_{k=n}^{n+m-1} A_{k}}\right) \sum_{j=n}^{n+m-1} B_{j} \\
& \leq\left(e^{\sum_{n=1}^{\infty} A_{n}}\right) d\left(x_{n}, p\right)+\left(e^{\sum_{n=1}^{\infty} A_{n}}\right) \sum_{j=n}^{n+m-1} B_{j} \\
\text { (17) } \quad & M d\left(x_{n}, p\right)+M \sum_{j=n}^{n+m-1} B_{j}
\end{aligned}
$$

where $M=e^{\sum_{n=1}^{\infty} A_{n}}$.

Since $\lim _{n \rightarrow \infty} d\left(x_{n}, F(S, T)\right)=0$, without loss of generality, we may assume that a subsequence $\left\{x_{n_{k}}\right\}$ of $\left\{x_{n}\right\}$ and a sequence $\left\{p_{n_{k}}\right\} \subset F(S, T)$ such that $d\left(x_{n_{k}}, p_{n_{k}}\right) \rightarrow 0$ as $k \rightarrow \infty$. Then for any $\varepsilon>0$, there exists $k_{\varepsilon}>0$ such that

$$
d\left(x_{n_{k}}, p_{n_{k}}\right)<\frac{\varepsilon}{4 M} \quad \text { and } \quad \sum_{j=n_{k_{\varepsilon}}}^{\infty} B_{j}<\frac{\varepsilon}{4 M}
$$

for all $k \geq k_{\varepsilon}$. 
For any $m \geq 1$ and for all $n \geq n_{k_{\varepsilon}}$, by (17) and (18), we have

$$
\begin{aligned}
d\left(x_{n+m}, x_{n}\right) \leq & d\left(x_{n+m}, p_{n_{k}}\right)+d\left(x_{n}, p_{n_{k}}\right) \\
\leq & M d\left(x_{n_{k}}, p_{n_{k}}\right)+M \sum_{j=n_{k_{\varepsilon}}}^{\infty} B_{j} \\
& +M d\left(x_{n_{k}}, p_{n_{k}}\right)+M \sum_{j=n_{k_{\varepsilon}}}^{\infty} B_{j} \\
= & 2 M d\left(x_{n_{k}}, p_{n_{k}}\right)+2 M \sum_{j=n_{k_{\varepsilon}}}^{\infty} B_{j} \\
< & 2 M \frac{\varepsilon}{4 M}+2 M \cdot \frac{\varepsilon}{4 M}=\varepsilon .
\end{aligned}
$$

This proves that $\left\{x_{n}\right\}$ is a Cauchy sequence in $K$. Thus, the completeness of $X$ implies that $\left\{x_{n}\right\}$ must be convergent. Assume that $\lim _{n \rightarrow \infty} x_{n}=q$. Since $K$ is closed, therefore $q \in K$. Next, we show that $q \in F(S, T)$. Now $\lim _{n \rightarrow \infty} d\left(x_{n}, F(S, T)\right)=0$ gives that $d(q, F(S, T))=0$. Since $F(S, T)$ is closed, $q \in F(S, T)$. This completes the proof.

Theorem 3.2. Let $K$ be a nonempty closed convex subset of a complete $C A T(0)$ space $X$ and let $S, T: K \rightarrow K$ be two uniformly L-Lipschitzian and generalized asymptotically quasi-nonexpansive mappings with sequences $\left\{u_{n}\right\},\left\{s_{n}\right\} \subset[0, \infty)$ such that $\sum_{n=1}^{\infty} u_{n}<\infty$ and $\sum_{n=1}^{\infty} s_{n}<\infty$. Suppose that $F(S, T) \neq \emptyset$. Let $\left\{x_{n}\right\}$ be defined by the iteration process (8). If $S$ and $T$ satisfy the following conditions:

(i) $\lim _{n \rightarrow \infty} d\left(x_{n}, S x_{n}\right)=0$ and $\lim _{n \rightarrow \infty} d\left(x_{n}, T x_{n}\right)=0$.

(ii) If the sequence $\left\{z_{n}\right\}$ in $K$ satisfies $\lim _{n \rightarrow \infty} d\left(z_{n}, S z_{n}\right)=0$ and $\lim _{n \rightarrow \infty} d\left(z_{n}, T z_{n}\right)=0$, then $\liminf _{n \rightarrow \infty} d\left(z_{n}, F(S, T)\right)=0$ or $\lim \sup _{n \rightarrow \infty} d\left(z_{n}, F(S, T)\right)=0$.

Then the sequence $\left\{x_{n}\right\}$ converges strongly to a point of $F(S, T)$.

Proof. It follows from the hypothesis that

$$
\lim _{n \rightarrow \infty} d\left(x_{n}, S x_{n}\right)=0 \text { and } \lim _{n \rightarrow \infty} d\left(x_{n}, T x_{n}\right)=0 .
$$

From (ii),

$$
\liminf _{n \rightarrow \infty} d\left(x_{n}, F(S, T)\right)=0 \quad \text { or } \quad \limsup _{n \rightarrow \infty} d\left(x_{n}, F(S, T)\right)=0 .
$$

Therefore, the sequence $\left\{x_{n}\right\}$ must converges to a point of $F(S, T)$ by Theorem 3.1. This completes the proof.

Theorem 3.3. Let $K$ be a nonempty closed convex subset of a complete $C A T(0)$ space $X$ and let $S, T: K \rightarrow K$ be two uniformly L-Lipschitzian and generalized asymptotically quasi-nonexpansive mappings with sequences $\left\{u_{n}\right\},\left\{s_{n}\right\} \subset[0, \infty)$ such that $\sum_{n=1}^{\infty} u_{n}<\infty$ and $\sum_{n=1}^{\infty} s_{n}<\infty$. Suppose 
that $F(S, T) \neq \emptyset$. Let $\left\{x_{n}\right\}$ be defined by the iteration process (8). If either $S$ or $T$ is semi-compact and $\lim _{n \rightarrow \infty} d\left(x_{n}, S x_{n}\right)=0$ or $\lim _{n \rightarrow \infty} d\left(x_{n}, T x_{n}\right)=$ 0 , then the the sequence $\left\{x_{n}\right\}$ converges strongly to a point of $F(S, T)$.

Proof. Suppose $T$ is semi-compact, there exists a subsequence $\left\{x_{n_{j}}\right\}$ of $\left\{x_{n}\right\}$ such that $x_{n_{j}} \rightarrow p \in K$. By hypothesis of the theorem $\lim _{n \rightarrow \infty} d\left(x_{n}, T x_{n}\right)=$ 0 , we have $\lim _{n_{j} \rightarrow \infty} d\left(x_{n_{j}}, T x_{n_{j}}\right)=0$. Hence, we have

$$
\begin{aligned}
d(p, T p) & \leq d\left(p, x_{n_{j}}\right)+d\left(x_{n_{j}}, T x_{n_{j}}\right)+d\left(T x_{n_{j}}, T p\right) \\
& \leq(1+L) d\left(p, x_{n_{j}}\right)+d\left(x_{n_{j}}, T x_{n_{j}}\right) \rightarrow 0 .
\end{aligned}
$$

Thus $p \in F(S, T)$. By (14),

$$
d\left(x_{n+1}, p\right) \leq\left(1+A_{n}\right) d\left(x_{n}, p\right)+B_{n} .
$$

Since by hypothesis $\sum_{n=1}^{\infty} A_{n}<\infty$ and $\sum_{n=1}^{\infty} B_{n}<\infty$, by Lemma 2.2, $\lim _{n \rightarrow \infty} d\left(x_{n}, p\right)$ exists and $x_{n_{j}} \rightarrow p \in F(S, T)$ gives that $x_{n} \rightarrow p \in F(S, T)$. This shows that $\left\{x_{n}\right\}$ converges strongly to a point of $F(S, T)$. This completes the proof.

We recall the following definition.

A mapping $T: K \rightarrow K$, where $K$ is a subset of a metric space $(X, d)$, is said to satisfy Condition (A) [25] if there exists a nondecreasing function $f:[0, \infty) \rightarrow[0, \infty)$ with $f(0)=0$ and $f(t)>0$ for all $t \in(0, \infty)$ such that $d(x, T x) \geq f(d(x, F(T)))$ for all $x \in K$ where $d(x, F(T))=\inf \{d(x, p): p \in$ $F(T) \neq \emptyset\}$.

We modify this definition for two mappings.

Two mappings $S, T: K \rightarrow K$, where $K$ is a subset of a metric space $(X, d)$, is said to satisfy Condition (B) if there exists a nondecreasing function $f:[0, \infty) \rightarrow[0, \infty)$ with $f(0)=0$ and $f(t)>0$ for all $t \in(0, \infty)$ such that $a_{1} d(x, S x)+a_{2} d(x, T x) \geq f(d(x, F(S, T)))$ for all $x \in K$ where $d(x, F(S, T))=\inf \{d(x, p): p \in F(S, T) \neq \emptyset\}$ and $a_{1}$ and $a_{2}$ are two nonnegative real numbers such that $a_{1}+a_{2}=1$. It is to be noted that Condition (B) is weaker than compactness of the domain $K$.

Remark 3.1. Condition (B) reduces to Condition (A) when $S=T$.

As an application of Theorem 3.1, we establish another strong convergence result employing Condition (B) as follows.

Theorem 3.4. Let $K$ be a nonempty closed convex subset of a complete $C A T(0)$ space $X$ and let $S, T: K \rightarrow K$ be two uniformly L-Lipschitzian and generalized asymptotically quasi-nonexpansive mappings with sequences $\left\{u_{n}\right\},\left\{s_{n}\right\} \subset[0, \infty)$ such that $\sum_{n=1}^{\infty} u_{n}<\infty$ and $\sum_{n=1}^{\infty} s_{n}<\infty$. Suppose 
that $F(S, T) \neq \emptyset$. Let $\left\{x_{n}\right\}$ be defined by the iteration process (8). Assume that $\lim _{n \rightarrow \infty} d\left(x_{n}, S x_{n}\right)=0$ and $\lim _{n \rightarrow \infty} d\left(x_{n}, T x_{n}\right)=0$. Let $S$ and $T$ satisfy Condition $(B)$, then the sequence $\left\{x_{n}\right\}$ converges strongly to a point of $F(S, T)$.

Proof. Since by hypothesis

$$
\lim _{n \rightarrow \infty} d\left(x_{n}, S x_{n}\right)=0 \text { and } \lim _{n \rightarrow \infty} d\left(x_{n}, T x_{n}\right)=0 .
$$

From Condition (B) and (20), we get

$$
\lim _{n \rightarrow \infty} f\left(d\left(x_{n}, F(S, T)\right) \leq a_{1} \cdot \lim _{n \rightarrow \infty} d\left(x_{n}, S x_{n}\right)+a_{2} \cdot \lim _{n \rightarrow \infty} d\left(x_{n}, T x_{n}\right)=0,\right.
$$

i.e., $\lim _{n \rightarrow \infty} f\left(d\left(x_{n}, F(S, T)\right)=0\right.$. Since $f:[0, \infty) \rightarrow[0, \infty)$ is a nondecreasing function satisfying $f(0)=0, f(t)>0$ for all $t \in(0, \infty)$, therefore we have

$$
\lim _{n \rightarrow \infty} d\left(x_{n}, F(S, T)\right)=0 .
$$

Now all the conditions of Theorem 3.1 are satisfied, therefore by its conclusion $\left\{x_{n}\right\}$ converges strongly to a point of $F(S, T)$. This completes the proof.

\section{Conclusion}

The class of mappings used in this article is more general than that of asymptotically nonexpansive, asymptotically quasi-nonexpansive and asymptotically quasi-nonexpansive mappings in the intermediate sense. Thus the results obtained in this article are good improvement and generalization of many known results from the previous work given in the existing literature.

\section{REFERENCES}

[1] R.P. Agarwal, D. O'Regan, D.R. Sahu, Iterative construction of fixed points of nearly asymptotically nonexpansive mappings, J. Nonlinear Convex Anal. 8(1) (2007), 6179 .

[2] M.R. Bridson and A. Haefliger, Metric spaces of non-positive curvature, Vol. 319 of Grundlehren der Mathematischen Wissenschaften, Springer, Berlin, Germany, 1999.

[3] K.S. Brown, Buildings, Springer, New York, NY, USA, 1989.

[4] R. Bruck, T. Kuczumow and S. Reich, Convergence of iterates of asymptotically nonexpansive mappings in Banach spaces with the uniform Opial property, Collo. Math. 65(2)(1993), 169-179.

[5] F. Bruhat and J. Tits, "Groups reductifs sur un corps local", Institut des Hautes Etudes Scientifiques. Publications Mathematiques, Vol. 41(1972), 5-251.

[6] S. Dhompongsa and B. Panyanak, On $\triangle$-convergence theorem in $C A T(0)$ spaces, Comput. Math. Appl. 56(10)(2008), 2572-2579.

[7] J.B. Diaz, F.T. Metcalf, On the structure of the set of subsequential limit points of successive approximations, Bull. Amer. Math. Soc. 73(1967), 516-519. 
[8] H. Fukhar-ud-din, S.H. Khan, Convergence of iterates with errors of asymptotically quasi-nonexpansive and applications, J. Math. Anal. Appl. 328(2007), 821-829.

[9] K. Goebel and W.A. Kirk, A fixed point theorem for asymptotically nonexpansive mappings, Proc. Amer. Math. Soc. 35(1972), 171-174.

[10] K. Goebel and S. Reich, Uniform convexity, hyperbolic geometry, and nonexpansive mappings, Vol. 83 of Monograph and Textbooks in Pure and Applied Mathematics, Marcel Dekker Inc., New York, NY, USA, 1984.

[11] S. Imnang and S. Suantai, Common fixed points of multi-step Noor iterations with errors for a finite family of generalized asymptotically quasi-nonexpansive mappings, Abstr. Appl. Anal. Vol. 2009, Article ID 728510, 14 pages, 2009.

[12] M.A. Khamsi and W.A. Kirk, An introduction to metric spaces and fixed point theory, Pure Appl. Math, Wiley-Interscience, New York, NY, USA, 2001.

[13] S.H. Khan and M. Abbas, Strong and $\triangle$-convergence of some iterative schemes in CAT(0) spaces, Comput. Math. Appl. Vol. 61(1)(2011), 109-116.

[14] A.R. Khan, M.A. Khamsi and H. Fukhar-ud-din, Strong convergence of a general iteration scheme in $C A T(0)$ spaces, Nonlinear Anal.: Theory, Method and Applications, Vol. 74(3)(2011), 783-791.

[15] W.A. Kirk, Fixed point theory in $C A T(0)$ spaces and $\mathbb{R}$-trees, Fixed Point Theory Appl. 2004(4)(2004), 309-316.

[16] W.A. Kirk, Geodesic geometry and fixed point theory, in Seminar of Mathematical Analysis (Malaga/Seville, 2002/2003), Vol. 64 of Coleccion Abierta, 195-225, University of Seville Secretary of Publications, Seville, Spain, 2003.

[17] W.A. Kirk, Geodesic geometry and fixed point theory II, in International Conference on Fixed point Theory and Applications, 113-142, Yokohama Publishers, Yokohama, Japan, 2004.

[18] Q.H. Liu, Iterative sequences for asymptotically quasi-nonexpansive mappings, J. Math. Anal. Appl. 259(2001), 1-7.

[19] Q.H. Liu, Iterative sequences for asymptotically quasi-nonexpansive mappings with error member, J. Math. Anal. Appl. 259(2001), 18-24.

[20] Y. Niwongsa and B. Panyanak, Noor iterations for asymptotically nonexpansive mappings in CAT(0) spaces, Int. J. Math. Anal. Vol. 4(13)(2010), 645-656.

[21] D.R. Sahu, J.S. Jung, Fixed point iteration processes for non-Lipschitzian mappings of asymptotically quasi-nonexpansive type, Int. J. Math. Math. Sci. 33(2003), 20752081.

[22] A. Şahin, M. Başarir, On the strong convergrnce of a modified S-iteration process for asymptotically quasi-nonexpansive mapping in $C A T(0)$ space, Fixed Point Theory Appl. (2013), 2013:12.

[23] G.S. Saluja, Strong convergence theorem for two asymptotically quasi-nonexpansive mappings with errors in Banach space, Tamkang J. Math. 38(1)(2007), 85-92.

[24] J. Schu, Weak and strong convergence to fixed points of asymptotically nonexpansive mappings, Bull. Austral. Math. Soc. 43(1)(1991), 153-159. 
[25] H.F. Senter, W.G. Dotson, Approximating fixed points of nonexpansive mappings, Proc. Amer. Math. Soc. 44(1974), 375-380.

[26] N. Shahzad, A. Udomene, Approximating common fixed points of two asymptotically quasi-nonexpansive mappings in Banach spaces, Fixed Point Theory Appl., Vol. 2006, Article ID 18909, Pages 1-10.

[27] K.K. Tan and H.K. Xu, Approximating fixed points of nonexpansive mappings by the Ishikawa iteration process, J. Math. Anal. Appl. 178(1993), 301-308.

[28] K.K. Tan and H.K. Xu, Fixed point iteration processes for asymptotically nonexpansive mappings, Proc. Amer. Math. Soc. 122(1994), 733-739.

Gurucharan Singh Saluja

Department of Mathematics

Govt. Nagarjuna P.G. College of Science

RAIPUR-492010 (C.G.)

INDIA

E-mail address: saluja1963@gmail.com 